\begin{tabular}{|l|l|l|}
\hline \multicolumn{2}{|c|}{ PublisherInfo } \\
\hline \hline PublisherName & $:$ & BioMed Central \\
\hline \hline PublisherLocation & $:$ & London \\
\hline \hline PublisherImprintName & $:$ & BioMed Central \\
\hline \hline
\end{tabular}

\title{
How RNA polymerase moves
}

\begin{tabular}{|l|l|l||}
\hline \multicolumn{2}{|c|}{ ArticleInfo } \\
\hline \hline ArticleID & $:$ & 5055 \\
\hline \hline ArticleDOI & $:$ & $10.1186 /$ gb-spotlight-20050128-01 \\
\hline \hline ArticleCitationID & $:$ & spotlight-20050128-01 \\
\hline \hline ArticleSequenceNumber & $:$ & 31 \\
\hline \hline ArticleCategory & $:$ & Research news \\
\hline ArticleFirstPage & $:$ & 1 \\
\hline \hline ArticleLastPage & $:$ & 3 \\
\hline \hline & & RegistrationDate : 2005-1-28 \\
\hline ArticleHistory & $:$ & OnlineDate \\
\hline \hline ArticleCopyright & $:$ & BioMed Central Ltd2005-1-28 \\
\hline \hline ArticleGrants & $:$ & \\
\hline \hline ArticleContext & $:$ & 130596611 \\
\hline \hline
\end{tabular}


Investigators may have uncovered the general mechanism that governs RNA polymerase movement (Cell 2004, 120:183-193), they report in the January 28 issue of Cell.

The finding "provides a framework for understanding how numerous external regulatory signals converge to change the properties of the RNA polymerase active site," co-author Evgeny Nudler of New York University told The Scientist.

Nudler and colleagues explored RNA polymerase's F bridge helix at its elongation complex's catalytic center. In 2001, Roger Kornberg at Stanford University and colleagues suggested the F bridge drives the enzyme forward by switching between its bent and straight conformations.

Using a genetic screen, the researchers isolated two mutations in Escherichia coli RNA polymerase's $\mathrm{G}$ loop, a region adjacent to the $\mathrm{F}$ bridge that recent studies suggested regulated $\mathrm{F}$ bridge conformation. One, G1136S, led to faster elongation as well as rendering RNA polymerase poorly responsive to pauses and terminators. The other, $\mathrm{I} 1134 \mathrm{~V}$, rendered the enzyme slow and overreactive at regulatory signals.

Using crosslinkers whose attachment points are sensitive to whether the $\mathrm{F}$ bridge is bent or straight, Nudler and colleagues found that I1 $134 \mathrm{~V}$ restricted F bridge motion by shifting it to its bent state and G1136S potentiated $\mathrm{F}$ bridge motion by boosting the rate of transition between bent and straight conformations. This suggests the $\mathrm{G}$ loop controls $\mathrm{F}$ bridge motion and governs RNA polymerase movement.

Kinetic simulations suggest RNA polymerase travels down DNA and RNA by a ratchet mechanism with two wedges, or pawls, that can restrict the ratchet's movements. The $\mathrm{F}$ bridge acts as a reciprocating pawl that bends and straightens to push RNA polymerase one nucleotide forward with respect to the nucleic acid scaffold and initiate the next cycle of substrate addition. The incoming substrate serves as a stationary pawl that keeps RNA polymerase from slipping backward.

The ratchet model argues the faster the F bridge oscillates between bent and straight, the greater the chance of incorporating incorrect substrates. As a test, Nudler and colleagues compared the wildtype and the two mutant RNA polymerases, monitoring misincorporation by incubating the enzymes with CTP, ATP, or 2'-deoxy-TTP instead of the correct substrate, complementary UTP. As the model predicted, the fast mutant was error prone while the slow mutant showed much greater fidelity than wildtype.

The model also reveals an intrinsic proofreading mechanism where the wrong substrates facilitate backtracking, giving the enzyme an opportunity to correct itself. Such backtracking ejects the wrong substrate before it can be incorporated into RNA, which the researchers observed using incorrect GMP and AMP.

"The data are absolutely beautiful," said Carlos Bustamante of the University of California at Berkeley, who did not participate in this study.

What remains is finding out how regulatory factors target the F bridge and $\mathrm{G}$ loop, which are mostly buried inside the enzyme, Nudler said. Some external flexible parts of RNA polymerase, such as the flap 
domain on the enzyme's second largest subunit, could serve as adaptors that transmit the signal to the Fbridge and G-loop unit. "We need to connect these parts together," he said.

Unlike proposed powerstroke mechanisms, where forward translocation is linked to substrate hydrolysis, this is a Brownian ratchet system, in which translocation occurs before phosphodiester bond formation and no energy other than that provided by thermal fluctuations is needed to propel RNA polymerase forward. Nudler and colleagues offer "pretty good evidence a Brownian ratchet is utilized, but a powerstroke mechanism remains a real possibility until we can measure RNA polymerase when it's elongating with both a very high structural resolution and a very high time resolution," said Rui Sousa of the University of Texas Health Science Center in San Antonio, who did not participate in this study.

For instance, "if the F bridge is undergoing this oscillation back and forth, it would be nice to label that part of the protein with FRET and actually see these changes," Bustamante told The Scientist.

\section{References}

1. Cell, [http://www.cell.com/]

2. Evgeny A. Nudler, [http://www.med.nyu.edu/Research/E.Nudler-res.html]

3. Structural basis of transcription: an RNA polymerase II elongation complex at 3.3 A resolution

4. Automata: Rachets, [http://www.automata.co.uk/ratchets.htm]

5. Carlos Bustamante, [http://alice.berkeley.edu/main/carlos.html]

6. Rui J. Sousa, [http://www.uthscsa.edu/faculty/sousa.html] 